\title{
Assessment of Virulence of Acremonium cucurbitacearum and Monosporascus cannonballus on Cucumis melo
}

\author{
B. D. Bruton, United States Department of Agriculture, Agricultural Research Service, South Central Agricultural \\ Research Laboratory, Lane, OK 74555; J. Garcia-Jimenez and J. Armengol, Unidad de Patologia Vegetal, Dpto. \\ de Produccion Vegetal, Universidad Politecnica, C de Vera s/n, 46020 Valencia, Spain; and T. W. Popham, United \\ States Department of Agriculture, Agricultural Research Service, Stillwater, OK 74074
}

\begin{abstract}
Bruton, B. D., Garcia-Jimenez, J., Armengol, J., and Popham, T. W. 2000. Assessment of virulence of Acremonium cucurbitacearum and Monosporascus cannonballus on Cucumis melo. Plant Dis. 84:907-913.

Assessment of plant response to inoculation with soilborne pathogens is essential for evaluation of fungal virulence. Combined plant responses (damage to hypocotyl, root-stem junction, primary root, secondary roots, and reduction in leaf area) used to derive a disease severity index (DSI) provided a functional assessment of both plant damage and pathogen virulence. Spanish isolates of Acremonium cucurbitacearum ranged from virulent to highly virulent on muskmelon cv. Magnum 45, whereas isolates from the Lower Rio Grande Valley (LRGV) of Texas ranged from weakly virulent to moderately virulent. Spanish isolates of Monosporascus cannonballus ranged from nonpathogenic to weakly virulent, whereas LRGV isolates ranged from weakly virulent to moderately virulent. Regression analysis of multiple inoculum densities established that CFU per gram of soil of 5, 10, 20, and 40 for M. cannonballus and $0.1 \times 10^{4}, 1 \times 10^{4}, 2 \times$ $10^{4}$, and $3 \times 10^{4}$ for $A$. cucurbitacearum, respectively, were adequate for virulence assessment of isolates of either fungus in greenhouse tests on seedlings. Seed planting depth had a significant effect on DSI. The 4-cm depth generally had smaller standard errors of the mean disease rating, indicating greater precision in determining isolate virulence.
\end{abstract}

Additional keywords: cantaloupe, inoculum density, leaf area index, root damage, vine decline

Soilborne diseases have become the yield-limiting factor in many cucurbit production areas around the world (7). Among these are a group of diseases known as vine declines, which can take the form of crown rot, root rot, sudden death, sudden wilt, wilt, and vine collapse. Cucurbit crops that develop vine decline generally exhibit no foliar symptoms until about 10 to 20 days before harvest (14). It has been suggested that some changes in cultural practices during the last 20 years have contributed greatly to the increase in number and severity of soilborne diseases of cucurbits (14). These cultural changes include introduction of hybrid cultivars, transplants, plastic mulch, drip irrigation, and increased plant density in absence of adequate rota-

Corresponding author: B. D. Bruton E-mail: bbruton-usda@lane-ag.org

Mention of a trademark, proprietary product, or vendor does not constitute a guarantee or warranty of the product by the USDA and does not imply its approval to the exclusion of other products or vendors that may also be suitable.

Accepted for publication 28 April 2000

Publication no. D-2000-0619-01R

This article is in the public domain and not copyrightable. It may be freely reprinted with customary crediting of the source. The American Phytopathological Society, 2000. tion. Transplants tend to decrease the severity of Fusarium wilt in watermelon but increase the severity of Monosporascus vine decline in muskmelon (7). Increased seed planting depth has been shown to increase hypocotyl rot in seedling muskmelon (19).

Two species, Monosporascus eutypoides and $M$. cannonballus, have been associated with vine decline of muskmelon and watermelon grown in hot semiarid environments $(7,29)$. Based on the existing information, M. cannonballus and M. eutypoides should be considered synonymous, with $M$. cannonballus taking precedence (7,27). In 1983, Reuveni et al. (38) first demonstrated that $M$. cannonballus was the cause of a vine decline of muskmelon in Israel. By 1997, M. cannonballus had been isolated from cucurbits in 11 countries (9). In the Lower Rio Grande Valley (LRGV) of Texas, M. cannonballus is clearly the primary cause of vine decline of muskmelon $(7,9,29,30)$. Monosporascus root rot and vine decline was reported in Spain in 1990, but no pathogenicity studies were reported $(23,24)$. More recently, reports of pathogenic and nonpathogenic Spanish isolates have been published, although critical information on the inoculation procedure and assessment of virulence is generally lacking $(15,16,25,26)$. Consequently, there has been some controversy as to the role of
M. cannonballus in vine decline of melons in Spain.

Garcia-Jimenez et al. $(16,17)$ reported a collapse and sudden death ("collapso" and "muerta subita") of melons in Spain caused by Acremonium cucurbitacearum. Since 1990, muskmelon production in the area of Valencia, Spain, has almost been abandoned due to Acremonium collapse (4). Gubler (19) first reported a hypocotyl rot of melons in California caused by $\mathrm{A}$. $\mathrm{Cu}$ curbitacearum but did not associate the disease with a late-season vine decline. More recently, A. cucurbitacearum has been associated with a vine decline of melons in the upper San Joaquin and Sacramento valleys of California $(8,20)$. In the LRGV of Texas, A. cucurbitacearum has been isolated from muskmelon and watermelon (12), although it does not appear to cause a detectable level of disease (7). Preliminary evidence indicated that isolates from Spain and California were similar in level of virulence, whereas isolates from Texas were generally less virulent (10).

Various techniques have been used to determine pathogenicity of $M$. cannonballus and A. cucurbitacearum. These include mixing fungal colonized agar with soil and planting seeds of the test plants $(17,22,30,36,40,41)$. Sand-oat hull mix or similar medium has been used as a substrate for fungal colonization and subsequently mixed ( $\mathrm{vol} / \mathrm{vol}$ or $\mathrm{vol} / \mathrm{wt}$ ) with soil in pots $(4,13,21,32,36)$. Fungal-colonized grain sorghum seeds incorporated into soil has been used to test pathogenicity (28), as well as a hydroponic system (17). In some cases, known inoculum densities (CFU/g of soil) have been used in pathogenicity studies $(3,4,10,11,13,19,32,38)$. In many instances, researchers did not adequately describe the method of inoculation $(8,20,26,29,35)$. In some studies comparing isolate virulence, inoculum density was determined and reported $(2,3,10)$; however, inoculum density was not reported for others $(25,28,29,35)$.

Muskmelon response to soilborne disease may be influenced by the stage of plant development, level of plant resistance, pathogen density, virulence, and environmental conditions (7). Accurate assessment of virulence in soilborne pathogens is necessary for monitoring gene introduction and/or genetic drift within the 
pathogen population and is a prerequisite for effective plant breeding programs. The purpose of this study was to (i) determine inoculum densities for evaluating pathogenicity and virulence among $A$. cucurbitacearum and $M$. cannonballus isolates, and (ii) determine appropriate seed planting depth for consistent disease reaction. Preliminary reports in the form of abstracts have been published $(12,37)$.

\section{MATERIALS AND METHODS}

Inoculum density-disease severity relationships. A. cucurbitacearum and $M$. cannonballus from Spain (three isolates of each fungus) and the LRGV of Texas (three isolates of each fungus) were arbitrarily selected to determine the optimum inoculum density to obtain the desired disease reaction to assess isolate virulence (Table 1). The fungi were previously isolated from muskmelon roots exhibiting symptoms of vine decline. Isolates were stored in glass vials containing sterilized artificial soil (Terra-Lite, Scotts-Sierra Hort. Products Co., Marysville, OH). A small aliquot of the fungal-colonized artificial soil mix was transferred to potato dextrose agar (PDA) and allowed to grow (under laboratory conditions) 7 days for $A$. cucurbitacearum and 5 days for $M$. cannonballus. Five PDA disks plus mycelium were transferred to a growth medium. The growth medium consisted of coarse sand ( 0.45 to $0.55 \mathrm{~mm}$ swimming pool filter sand, Wedron Silica Co., Wedron, IL) and ground oat hulls (Avena sativa) (The Quaker Oats Co., Chicago, IL). Five hundred milliliters of sand was mixed with 45 $\mathrm{g}$ of ground oat hulls in a 1-liter flask. After adding $100 \mathrm{ml}$ of water, the contents were autoclaved three times for $1 \mathrm{~h}$, skipping 1 to 2 days between each autoclaving. Once the fungal colonies achieved about 5 $\mathrm{cm}$ diameter, the contents were shaken vigorously to thoroughly mix the inoculum and allowed to grow. After a total of 28 days, the contents were thoroughly mixed again, and a subsample ( $1 \mathrm{~g})$ was removed to determine CFU per gram of inoculum. The subsample was added to $99 \mathrm{ml}$ of sterile $2 \%\left(1\right.$ in $\left.10^{2}\right)$ hydroxy-ethyl cellulose (Aldrich, Milwaukee, WI) with a stir bar and placed on a stirplate for $1 \mathrm{~min}$. Beginning with the dilution of 1 in $10^{2}$, a serial dilution was done to 1 in $10^{7}$ for $A$. cucurbitacearum and 1 in $10^{4}$ for $M$. cannonballus. One milliliter was added to each of five plates per dilution and incubated for 3 days at room temperature to determine CFU per gram of inoculum. During the 3day incubation period, the original inoculum was stored at ca. $23^{\circ} \mathrm{C}$ in the laboratory. Based on preliminary studies, inoculum densities of $0.0,0.5 \times 10^{4}, 1 \times$ $10^{4}, 2 \times 10^{4}, 3 \times 10^{4}, 4 \times 10^{4}$, and $5 \times 10^{4}$ $\mathrm{CFU} / \mathrm{g}$ of soil were used for A. cucurbitacearum, and of $0,5,10,20,30,40$, and 50 $\mathrm{CFU} / \mathrm{g}$ of soil were used for $M$. cannonballus.

Soil (methyl bromide sterilized river sand) for five pots was infested with isolates representing A. cucurbitacearum or M. cannonballus (Table 1) for each inoculum density. Ten cantaloupe seeds (cv. Magnum 45) were placed on top of the soil, and an additional $4 \mathrm{~cm}$ of infested soil was added to fill the pot $(14.5 \times 11.0 \mathrm{~cm})$. The pots were moved to a greenhouse and thinned to five plants per pot following emergence. Soil temperature in the center of the pots was recorded every minute, averaged over the hour, and recorded for each 24-h period using a CR10 data logger (Campbell Scientific, Inc., Logan, UT). Each pot was fertilized weekly with $1 \%$ Peters 20:20:20 (Grace-Sierra Hort. Products, Milpitas, CA). After 28 days, the soil was gently washed away to expose the roots for disease assessment.

Disease rating indices were used for the hypocotyl $(\mathrm{RH})$ where $1=$ healthy with no lesions or discoloration, 2 = slight discoloration, $3=$ moderate discoloration and/or with lesions, $4=$ moderate maceration, and 5 = severe maceration; for the stem-root junction (RSR) where $1=$ healthy with no lesion or discoloration, 2 = slight discoloration, $3=$ moderate discoloration but firm, $4=$ moderate discoloration and slight maceration, $5=$ severe discoloration and macerated; for the primary root (R1R) where $1=$ healthy with no lesions, $2=$ up to $25 \%$ with slight discoloration, $3=>25 \%$ slightly discolored or with lesions, $4=$ moderate discoloration and/or slight mac-

Table 1. Description of fungal isolates used in inoculation studies

\begin{tabular}{crllc}
\hline Fungus & Isolate no. & \multicolumn{1}{c}{ C. melo/group } & Location isolated & Year isolated \\
\hline Acremonium cucurbitacearum & & & \\
SP 934941 & inodorus & La Llosa (Castellón) & 1993 \\
SP 875033 & inodorus & Pueblo Nuevo (Valencia) & 1987 \\
SP 934943 & inodorus & El Romani (Valencia) & 1993 \\
TX 951054 & cantaloupensis & Starr County (Texas) & 1995 \\
TX 941022 & cantaloupensis & Hidalgo County (Texas) & 1994 \\
TX 951065 & cantaloupensis & Starr County (Texas) & 1995 \\
SP 935039 & inodorus & El Romani (Valencia) & 1993 \\
SP 935043 & inodorus & El Romani (Valencia) & 1993 \\
SP 935051 & inodorus & La Llosa (Castellón) & 1993 \\
TX 902020 & cantaloupensis & Starr County (Texas) & 1990 \\
TX 912035 & cantaloupensis & Starr County (Texas) & 1991 \\
TX 921999 & inodorus & Starr County (Texas) & 1992 \\
\hline
\end{tabular}

eration, $5=$ severe discoloration and/or macerated; and for the secondary roots (R2R) where $1=$ healthy with no lesion or discoloration, 2 = slight discoloration, $3=$ slight discoloration with up to $25 \%$ root mass reduction, $4=$ moderate discoloration with up to $50 \%$ root mass reduction, $5=$ severe discoloration with $>50 \%$ root mass reduction. The first two true leaves were removed from each plant, and leaf area was obtained using a LI-COR LI-3100 area meter (LI-COR, Inc., Lincoln, NE). Isolations were made from plants from representative treatments to verify the presence of the inoculated fungus. Each of the experiments was repeated.

Seed planting depth study. To determine the effects of seed planting depth on disease severity of Magnum 45, seeds were planted 2, 4, or $6 \mathrm{~cm}$ deep. The soil was infested with isolates of A. cucurbitacearum (SP 934943 or TX $941022\left[1 \times 10^{4}\right.$ CFU/g of soil]) or M. cannonballus (SP 935039 or TX 912035 [20 CFU/g of soill]) according to methods described above. The experiment was conducted twice with disease ratings taken as previously described.

Statistical analysis. A disease severity index (DSI) was derived as follows: $\mathrm{DSI}_{i}=$ $\left(\mathrm{RH}_{i}+\mathrm{RSR}_{i}+\mathrm{R} 1 \mathrm{R}_{i}+\mathrm{R}_{2} \mathrm{R}_{i}+\mathrm{RLA}_{i}\right) / 5$ is the disease severity index for $i$ th plant. For the $i$ th plant, $\mathrm{RH}_{i}, \mathrm{RSR}_{i}, \mathrm{R}_{1} \mathrm{R}_{i}$, and $\mathrm{R}_{2} \mathrm{R}_{i}$, respectively, are the disease ratings for the hypocotyl, root-stem junction, primary root, and secondary roots.

The ratio of average leaf area of the first two true leaves on the $i$ th inoculated plant $\left(\mathrm{ILA}_{i}\right)$ to the leaf area of the first two true leaves on control plants $\left(\mathrm{CLA}_{\mathrm{avg}}\right)$ is subtracted from 1 to give the amount of reduction relative to the control $\left(R_{i}=1-\right.$ $\mathrm{ILA}_{i} / \mathrm{CLA}_{\mathrm{avg}}$ ). $\mathrm{RLA}_{i}$, scaled reduction in leaf area, is the linear interpolation of the $R_{i}$ on a scale from 1 to 5 , where the scale points are: $1=$ less than $20 \%, 2=20$ to $40 \%, 3=41$ to $60 \%, 4=61$ to $80 \%$, and 5 $=$ more than $80 \%$ leaf area reduction. The $\mathrm{DSI}_{i}$ rating is the average of the four root ratings plus $\mathrm{RLA}_{i}$. For each isolate, average DSI over all inoculum densities (ID) was compared to provide a relative scale of virulence for the isolates tested. DSI data were analyzed using both analysis of variance (ANOVA) and regressions. PROC GLM (SAS Institute, Cary, NC) were used to test for the effects of inoculum density and isolates on DSI values. With regressions, separate fitting was done for each isolate for DSI versus ID using as the model function, DSI $=1+b(\mathrm{ID})^{2}$, fitted using PROC MODEL (SAS Institute). Using the numerical constant of 1 maintains the 1 to 5 scale used for the disease rating system.

Linear regressions of RH, RSR, R1R, R2R, RLA, and DSI over ID were performed for each isolate in the study. The regression of DSI $=a+b$ (ID) provided two parameter estimates: $a$, the intercept or level (overall level of virulence), and $b$, the 


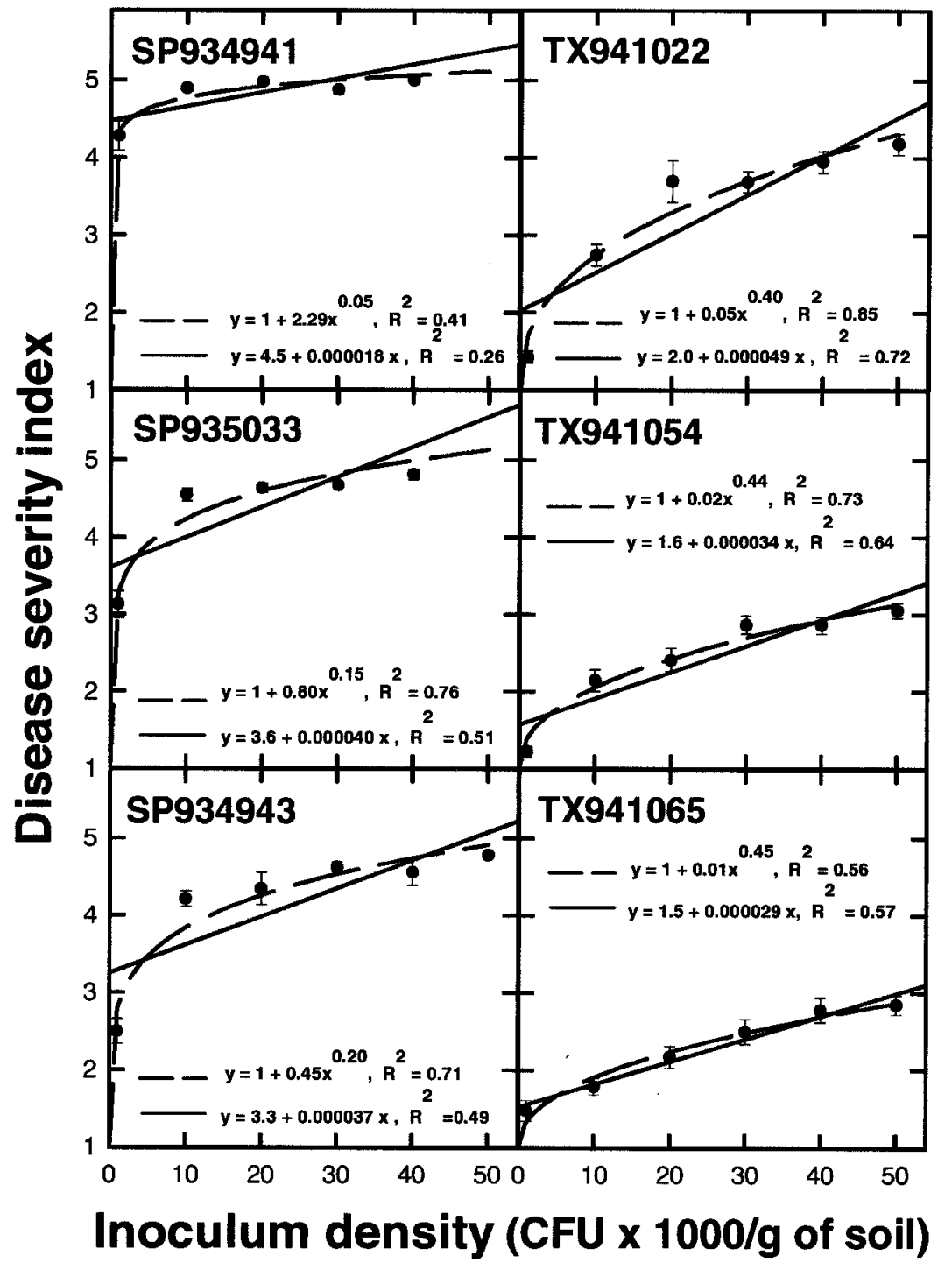

Fig. 1. Disease severity index (DSI) on muskmelon cv. Magnum 45, 28 days after inoculation with different inoculum densities (CFU/g of soil) of Acremonium cucurbitacearum. Derivation of DSI is discussed in Materials and Methods. Isolates with a DSI rating (intercept) of 1.0 to 1.9 were weakly virulent; 2.0 to $2.9=$ moderately virulent; 3.0 to $3.9=$ virulent; and 4.0 and above $=$ highly virulent . Bars represent standard errors of the mean for pooled data from two experiments. slope or rate (rate of increase in DSI due to increasing ID). The null hypothesis that parameter estimates were equal to zero was tested with a $t$ test $(P \leq 0.05)$. Covariance analysis was used to compare the linear regressions of all pairs of isolates within a genus. Isolates with a DSI rating intercept of 1.0 to 1.9 were judged to be nonpathogenic to weakly virulent, 2.0 to 2.9 were moderately virulent, 3.0 to 3.9 were virulent, and 4.0 and above were highly virulent. Planting depth data were analyzed by ANOVA with independent effects: isolates, planting depth, and isolate by planting depth interaction. Second order polynomial regressions were performed to examine the effects of planting depth with respect to isolate. Effects were judged to be significant when $P \leq 0.05$.

\section{RESULTS}

Inoculum density-disease severity relationships. Six A. cucurbitacearum isolates (three from Spain and three from LRGV) were evaluated for pathogenicity and level of virulence (Table 1). Equally weighted averages of the four root ratings and a scaled reduction in leaf area of the first two true leaves allowed derivation of a single value for DSI. The power curve showed that increasing inoculum density beyond $1 \times$ $10^{4}$ resulted in little increase in DSI for Spanish isolates of A. cucurbitacearum, whereas greater response was observed from LRGV isolates with increasing inoculum densities (Fig. 1).

Slopes of responses of individual plant components regressed over increasing inoculum densities showed the effects of inoculum density on each plant component (Table 2), while slope of DSI regressed over increasing inoculum densities showed overall effects. The intercepts provided estimates of fungal virulence with respect to each plant component, while the inter-

Table 2. Plant damage assessment using slope and intercept estimates from linear regression of plant damage ratings $(\mathrm{RH}=\mathrm{hypocotyl}$; RSR $=$ stem-root junction; R1R = primary root; R2R = secondary roots), scaled leaf area reduction (RLA), and disease severity index (DSI) over inoculum densities for Acremonium cucurbitacearum and Monosporascus cannonballus

\begin{tabular}{|c|c|c|c|c|c|c|c|c|c|c|c|c|c|c|c|c|c|c|}
\hline & \multicolumn{3}{|c|}{ RH } & \multicolumn{3}{|c|}{ RSR } & \multicolumn{3}{|c|}{ R1R } & \multicolumn{3}{|c|}{$\mathbf{R} 2 \mathbf{R}$} & \multicolumn{3}{|c|}{ RLA } & \multicolumn{3}{|c|}{ DSI } \\
\hline & Inter. & Slope & $R^{2 \mathbf{a}}$ & Inter. & Slope & $R^{2}$ & Inter. & Slope & $R^{2}$ & Inter. & Slope & $R^{2}$ & Inter. & Slope & $R^{2}$ & Inter. & Slope & $R^{2}$ \\
\hline \multicolumn{19}{|c|}{ Acremonium cucurbitacearum } \\
\hline SP 934943 & $3.2 * \mathrm{~b}$ & $0.000044 *$ & 0.44 & $4.1 *$ & $0.000023^{*}$ & 0.28 & $3.8^{*}$ & $0.000031^{*}$ & 0.35 & $3.3^{*}$ & $0.000042 *$ & 0.42 & $2.0^{*}$ & $0.000042 *$ & 0.58 & $3.3^{*}$ & $0.000037^{*}$ & 0.49 \\
\hline SP 935033 & $3.9^{*}$ & $0.000041 *$ & 0.34 & $4.3^{*}$ & $0.000025^{*}$ & 0.39 & $4.0^{*}$ & $0.000035^{*}$ & 0.42 & $3.7^{*}$ & $0.000046 *$ & 0.47 & $2.2 *$ & $0.000052 *$ & 0.45 & $3.6^{*}$ & $0.000040^{*}$ & 0.51 \\
\hline 4941 & $4.8^{*}$ & 0000 & 0.08 & $4.9^{*}$ & 0.000005 & 0.07 & $4.8^{*}$ & 0.000007 & 0.09 & $4.8^{*}$ & 0.000010 & 0.06 & $3.1^{*}$ & $0.000061 *$ & 0.37 & $4.5^{*}$ & $0.000018^{*}$ & 0.26 \\
\hline 1065 & $51.9^{*}$ & $0.000051 *$ & 0.52 & $1.6 *$ & $0.000025^{*}$ & 0.40 & $1.4^{*}$ & $0.000031 *$ & 0.45 & $1.5^{*}$ & $0.000037^{*}$ & 0.66 & 1.1 & 0.000002 & 0.02 & $1.5^{*}$ & $0.000029 *$ & 0.57 \\
\hline TX 951054 & $42.0^{*}$ & $0.000051 *$ & 0.66 & $1.6^{*}$ & $0.000037 *$ & 0.61 & $1.7 *$ & $0.000039^{*}$ & 0.52 & $1.6^{*}$ & $0.000038^{*}$ & 0.55 & 1.1 & $0.000006 *$ & 0.08 & $1.6^{*}$ & $0.000034 *$ & 0.64 \\
\hline TX 941022 & $23.2^{*}$ & $0.000041^{*}$ & 0.42 & $2.3^{*}$ & $0.000064 *$ & 0.70 & $1.8^{*}$ & $0.000068^{*}$ & 0.70 & $1.3^{*}$ & $0.000072 *$ & 0.77 & $1.6^{*}$ & 0.000005 & 0.03 & $2.0^{*}$ & $0.000049 *$ & 0.72 \\
\hline \multicolumn{19}{|c|}{ Monosporascus cannonballus } \\
\hline SP 935051 & $1.0^{*}$ & 0.0002 & 0.00 & $.1^{*}$ & -0.0012 & 0.01 & $1.1 *$ & 0.0037 & 0.03 & $1.1^{*}$ & 0.0009 & 0.004 & 1.1 & 0.0008 & 0.00 & 1.1 & 0.0009 & 0.01 \\
\hline SP 935043 & $1.4^{*}$ & -0.0076 & 0.01 & $1.3^{*}$ & -0.0089 & 0.03 & $1.4^{*}$ & $0.0485^{*}$ & 0.24 & $1.1^{*}$ & $0.0537 *$ & 0.26 & 1.3 & -0.0019 & 0.00 & 1.3 & 0.0168 & 0.05 \\
\hline SP 935039 & $1.4^{*}$ & $0.0202 *$ & 0.14 & $1.3^{*}$ & $0.0172^{*}$ & 0.11 & $1.7^{*}$ & $0.0332 *$ & 0.19 & $1.6^{*}$ & $0.0240 *$ & 0.16 & 1.0 & 0.0046 & 0.03 & $1.4^{*}$ & $0.0198 *$ & 0.16 \\
\hline TX 902020 & $1.1^{*}$ & 0.0029 & 0.01 & $1.3^{*}$ & -0.0003 & 0.00 & $1.4^{*}$ & $0.0176^{*}$ & 0.12 & $1.4^{*}$ & $0.0142 *$ & 0.09 & 1.3 & -0.0001 & 0.00 & 1.3 & 0.0069 & 0.04 \\
\hline & $2.2^{*}$ & $0.0282 *$ & 0.09 & $1.8^{*}$ & $0.0387^{*}$ & 0.19 & $2.5^{*}$ & & 0.46 & 2.2 & & 0.44 & 1.0 & 0.0269 & 0.35 & $1.9^{*}$ & & 0.29 \\
\hline TX 912035 & $5 \quad 3.1^{*}$ & 0.0158 & 0.03 & $2.8 *$ & $0.0235^{*}$ & 0.08 & $3.4^{*}$ & $0.0339 *$ & 0.47 & $3.0^{*}$ & $0.0338^{*}$ & 0.52 & $1.5^{*}$ & 0.0193* & 0.18 & $2.8^{*}$ & $0.0245^{*}$ & 0.20 \\
\hline
\end{tabular}

${ }^{a} R^{2}$ is the coefficient of determination of plant damage ratings or indexes due to changes in $\mathrm{CFU}$

$\mathrm{b} *$ indicates rejection of the null hypothesis, parameter $=0$, in the linear regression of response of variables (RH, RSR, R1R, R2R, RLA, and DSI) to different inoculum densities. 
cept for DSI provided an overall estimation of fungal virulence. The individual intercepts showing the greatest damage caused by $A$. cucurbitacearum tended to be at the stem-root junction and hypocotyl (Table 2). Based on DSI, SP 934941 (intercept 4.5) was judged highly virulent. SP 934943 and SP 935033 (intercepts 3.3 and 3.6, respectively) were judged as virulent. TX 941022 was judged moderately virulent (intercept 2.0), and TX 941054 and TX 941065 were judged weakly virulent (intercepts 1.6 and 1.5 , respectively) but responsive to increasing inoculum densities.

For the six $M$. cannonballus isolates (three from Spain and three from LRGV), the power curve model showed that increasing the inoculum density beyond 20 $\mathrm{CFU} / \mathrm{g}$ of soil generally resulted in little increase in DSI (Fig. 2). Inoculum densities above 30 were not used for isolate SP 935043 because the initial inoculum was insufficient to obtain the desired final concentration.

Examination of individual intercepts showed the greatest damage caused by $M$. cannonballus to be the primary and secondary roots (Table 2). Based on DSI, TX 912035 (intercept 2.8) was judged moderately virulent, whereas SP 935051 was nonpathogenic with an intercept of 1.1 and essentially no slope. All remaining isolates had intercepts ranging between 1.3 and 1.9 and were judged weakly virulent. Increasing inoculum density resulted in higher DSI for isolates TX 912035, TX 921999, and SP 935043, while the low slope values for SP 935051 and TX 902020 showed little change in DSI over increasing inoculum density.

For both fungal pathogens, covariance analysis indicated that the regressions were different for all possible pairs of isolates. Positive slopes demonstrated an increase in

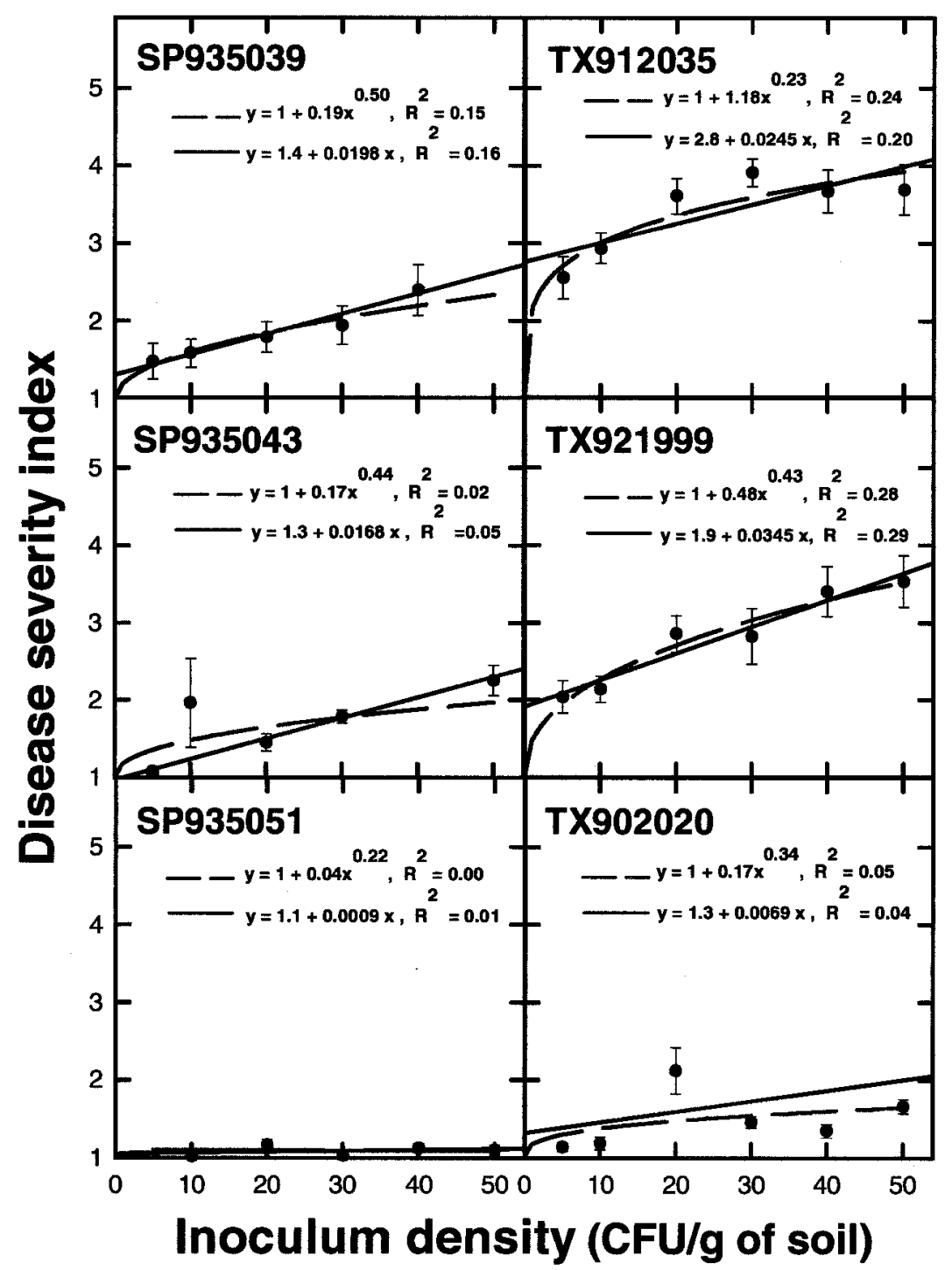

Fig. 2. Disease severity index (DSI) on muskmelon cv. Magnum 45, 28 days after inoculation with different inoculum densities (CFU/g of soil) of Monosporascus cannonballus. Derivation of DSI is discussed in Materials and Methods. Isolates with a DSI rating (intercept) of 1.0 to 1.9 were weakly virulent; 2.0 to $2.9=$ moderately virulent; 3.0 to $3.9=$ virulent; and 4.0 and above $=$ highly virulent. Bars represent standard errors of the mean for pooled data from two experiments. plant damage with increasing inoculum density. ANOVA of DSI, at specific inoculum densities, indicated significant differences between some isolates. However, when an intercept scale was defined to match the scales of individual plant responses, isolates were often placed in the same virulence category. Due to differential response to increasing inoculum densities, a single inoculum density may be inadequate for isolate comparisons. This methodology permits assessment of relative virulence as well as range of virulence within the selected pathogen population, but it would not allow prediction of performance of unknown isolates.

Disease response to planting depth. For A. cucurbitacearum, ANOVA of disease indices and plant measurements showed that there were significant isolate and planting depth effects. Planting depth had no effect on average leaf area (data not shown). Planting depth by isolate interaction was significant for DSI. The greatest changes in DSI were observed as planting depth increased from 2 to $4 \mathrm{~cm}$, with little change observed as depth was increased to $6 \mathrm{~cm}$ (Fig. 3). For M. cannonballus, significant isolate effects were observed for average leaf area (data not shown). For disease indices and DSI, the isolate by planting depth interaction was significant. The highest DSI ratings were observed at a planting depth of $4 \mathrm{~cm}$ for the more virulent isolate (TX 912035). For the weakly virulent isolate (SP 935039), the highest ratings were observed at planting depth of $6 \mathrm{~cm}$. Greater variability in disease ratings and DSI were generally observed at the 2 and $6 \mathrm{~cm}$ planting depth for both A. cucurbitacearum and $M$. cannonballus isolates.

The diurnal soil temperature ranged between 23 and $33^{\circ} \mathrm{C}$ during the experiments. Analysis of variance revealed no significant effects between experiments for either fungal pathogen.

\section{DISCUSSION}

Resistance or tolerance is a critical aspect in the management of soilborne diseases in cucurbits. Knowledge of the range of virulence within a pathogen population is essential for an effective breeding program requiring a reliable means of assessing virulence. Regression of plant responses over multiple inoculum densities provided functional virulence comparisons for A. cucurbitacearum and M. cannonballus on muskmelon. Combining the disease ratings on the hypocotyl, stem-root junction, primary root, secondary roots, and reduction of the first two true leaves accorded a comprehensive estimation of plant response to inoculation. With multiple disease variables, it may be possible to identify specific areas of plant damage for some soilborne pathogens as demonstrated in the present study. Other researchers have noted that $A$. cucurbitacearum caused the greatest damage to seedlings at the stem- 
root junction $(1,4,13,16,17)$, whereas $M$. cannonballus caused the greatest damage to the primary root $(30,34)$. Seed planting depth of $4 \mathrm{~cm}$ gave smaller standard errors of the mean disease rating, resulting in greater precision for determining isolate virulence. Previous studies demonstrated that seed depth of $2 \mathrm{~cm}$ often gave variable disease severity due to the redistribution of sand and seed movement during watering (unpublished data). Gubler (19) noted that seedling disease, caused by A. cucurbitacearum, was more severe as seeding depth increased from 2.5 to $7.5 \mathrm{~cm}$.

Historically, pathogenicity of $M$. cannonballus and A. cucurbitacearum isolates has been determined without knowledge of inoculum density $(8,17,22,26,28,30,36,40,41)$. Furthermore, virulence comparisons among isolates have been made without accounting for inoculum density $(25,29,33,35,42)$. In previous greenhouse studies using a measured amount ( $\mathrm{vol} / \mathrm{vol})$ of $M$. cannonballus-colonized inoculum per pot, as first described by Mertely et al. (31), disease reaction ranged from no disease to $100 \%$ postemergence damping-off (B. D. Bruton, unpublished data). Because M. cannonballus isolates colonize the sand/oat hull growth medium at dissimilar rates, the inoculum density in the growth medium can vary greatly. For example, using a measured volume of $M$. cannonballuscolonized growth medium per pot (one inoculum density), the inoculum density in the present study would have ranged from 34 to $369 \mathrm{CFU} / \mathrm{g}$ of soil, depending on isolate. Similarly, the inoculum density for A. cucurbitacearum would have ranged from 8,000 to $300,000 \mathrm{CFU} / \mathrm{g}$ of soil, depending on isolate. Consequently, pathogenicity evaluation and studies of relative virulence among isolates could be deceptive without equivalent inoculum densities. For critical virulence comparisons between isolates of either fungus, at least four different inoculum densities should be used. It is possible to define a curve with only three levels; however, it was not always possible to determine the range where the response transitions to slowly increasing DSI with less than four inoculum densities. The DSI range most responsive to inoculum density is from 0 to the level where the line begins to flatten, which varies among isolates. Inoculum densities of 5 , 10,20 , and $40 \mathrm{CFU} / \mathrm{g}$ of soil should be sufficient for $M$. cannonballus, and inoculum densities of $0.1 \times 10^{4}, 1 \times 10^{4}, 2 \times 10^{4}$, and $3 \times 10^{4} \mathrm{CFU} / \mathrm{g}$ of soil should work for A. cucurbitacearum. For simply determining pathogenicity of fungal isolates, 20 and $1.0 \times 10^{4} \mathrm{CFU} / \mathrm{g}$ of soil are recommended for M. cannonballus and A. cucurbitacearum, respectively. Ability to establish range of virulence within the pathogen population may be thwarted when using excessive inoculum densities, since moderately virulent isolates may appear to be highly virulent. The inability to discrimi- nate between moderately virulent and highly virulent isolates may lead to an unfortunate choice of test isolates in germ plasm evaluation. Similar studies have recommended inoculum densities of 20 and $1.0 \times 10^{4} \mathrm{CFU} / \mathrm{g}$ of soil for evaluating California isolates of $M$. cannonballus and A. cucurbitacearum, respectively (11). This is also consistent with Armengol (2) and Armengol et al. (3), who showed that Spanish isolates of A. cucurbitacearum produced severe root rot to muskmelon cv.

Acremonium — SP 934943 - TX 941022

Piel de Sapo using inoculum densities of $1.0 \times 10^{4} \mathrm{CFU} / \mathrm{g}$ of soil or higher.

$\mathrm{CFU}$ in the present study were based on mycelial fragments, conidiospores, and chlamydospores for A. cucurbitacearum. $\mathrm{CFU}$ for $M$. cannonballus isolates were based solely on mycelial fragments, although some perithecia containing ascospores were produced by isolates SP 935051 and TX 912035. The number of ascospores contributed by the two isolates averaged less than 2.5 per gram of soil at
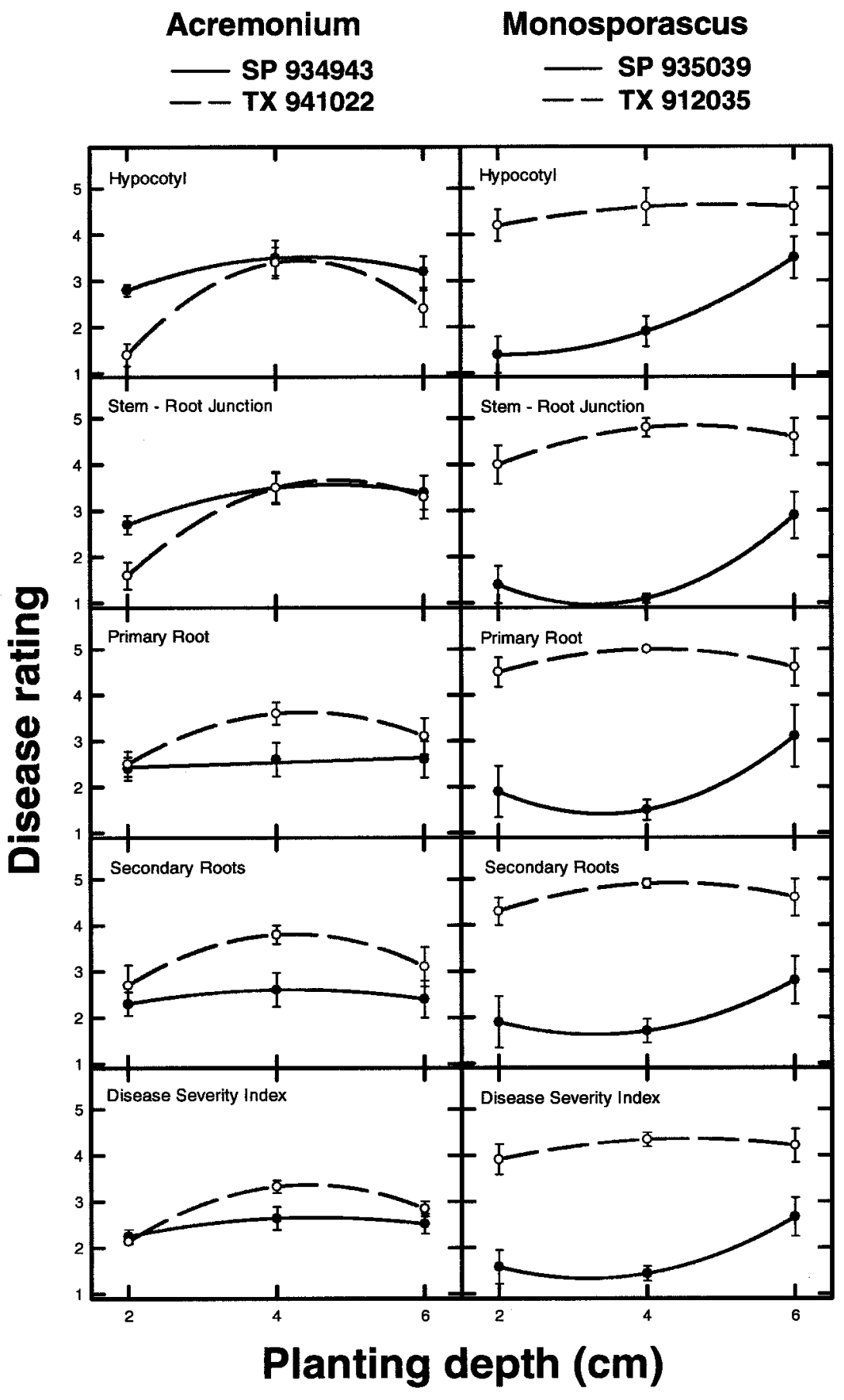

Fig. 3. Effect of seed planting depth in response to inoculation with Acremonium cucurbitacearum (SP 934943 or TX 941022 [1 × 104 CFU/g of soil]) or Monosporascus cannonballus (SP 935039 or TX 912035 [20 CFU/g of soil]) with means and standard errors at different planting depths for four disease parameters and overall disease severity index (DSI). Results represent combined data from the two experiments. Quadratic polynomial regressions were fitted to illustrate the effects of planting depth on disease reaction and DSI. 
the inoculum density of $5 \mathrm{CFU} / \mathrm{g}$ of soil. Since ascospores do not germinate on agar, they were not counted as part of the inoculum. In laboratory studies at $25^{\circ} \mathrm{C}$, Stanghellini et al. (39) demonstrated that ascospores do germinate in soil in the presence of muskmelon roots. Approximately $4 \%$ of the ascospores germinated and infected melon roots after 12 days. An inoculum density of approximately 600 ascospores per $\mathrm{cm}^{3}$ ( 475 ascospores per gram of soil) was used to inoculate $C$. melo cultivars in which the mean root disease rating was 2 , based on a 0 to 4 scale (32). Mertely et al. (33) reported no differences in root disease at the end of the season when comparing fields with initial inoculum densities of 4 and 10.8 ascospores per gram of soil. In addition, Stanghellini et al. (39) noted that commercial muskmelon fields with and without a history of vine decline had similar numbers of ascospores per gram of soil. The role of ascospores in the epidemiology of Monosporascus vine decline is not fully understood. In future studies, inoculum should be grown for 14 to 20 days to avoid ascospores in the inoculum.

Neither the power curve model nor linear regression alone may be adequate for determination of relative virulence. However, both used in tandem can provide effective interpretation of data using multiple inoculum densities. DSI plotted over increasing inoculum densities increased rapidly through lower inoculum densities to a level where additional increases of inoculum resulted in small increases in disease severity. Fitting the power curve model allowed determination of the range where increases of inoculum density resulted in little or no increase in response. However, slope and intercept estimates of linear regressions over increasing inoculum densities may be influenced by a disproportionate number of observations in the rapidly or slowly increasing portion of the disease response. Grogan et al. (18) stated that disease incidence of $100 \%$ is not attained even though very high levels of inoculum are present; the curves approach a plateau, and additional inoculum produces little or no increase in disease incidence. The leveling-off of disease incidence indicates that some factors other than inoculum density are limiting; i.e., a portion of the plant population may be highly resistant or some plants have escaped because of nonrandom distribution of inoculum (18). A similar observation was made in the present study: i.e., incomplete susceptibility of host or limited sites for infection. If inoculum densities include the transition (inflection point) from rapidly to slowly increasing disease response, linear regression can be used as a quick and easily interpreted method to evaluate virulence. Regression analysis provided a better estimate of isolate virulence than ANOVA (data not shown). Baker (5) and Baker et al. (6), attempting to linearize the observed curvilinear response, used several transformations including logits and probits to relate infection to inoculum density. Assuming normal distribution of errors about estimates of responses to increases of inoculum density, the power curve model was fitted by nonlinear regression, avoiding transformations in the present study.

For cucurbit root rot pathogens, reduction in leaf area of the first two true leaves may be preferable to taking root weight due to the difficulty in obtaining all the roots and the great amount of variability that is normally experienced. Previous host range studies with $A$. cucurbitacearum demonstrated that root weight was insufficient for estimating plant damage (13). In addition, root weight has been shown to be a poor estimate of plant damage by $M$. cannonballus in other studies $(30,32)$. Adventitious roots produced along the hypocotyl of diseased plants often obscure actual reduction in root mass of primary and secondary roots. Alone, area of the first two true leaves (RLA) is insufficient to estimate plant damage. Combining ratings of damage to the hypocotyl (RH), stemroot junction (RSR), primary root (R1R), and secondary roots (R2R) with a scaled leaf area reduction provided a useful method for assessment of isolate virulence or plant damage. Perhaps this study can provide a basis for the development of a universal testing system (7) to standardize methods for evaluating soilborne pathogens of cucurbits.

\section{ACKNOWLEDGMENTS}

We thank A. Dillard, D. Baze, R. Sales Junior, and G. Martinez-Ferrer for their technical assistance throughout this work and M. Biernacki, R. Cohen, J. Damicone, J. D. Duthie, G. Holmes, and M. E. Stanghellini for technical review. We also thank the Spanish Comision Interministerial de Ciencia y Tecnologia for financial support (AGR90-0816-CO2-01 and AGF94-0520) and the Quaker Oat Co., Chicago, IL, for the ground oat hulls.

\section{LITERATURE CITED}

1. Alfaro-Garcia, A., Armengol, J., Bruton, B. D., Gams, W., Garcia-Jiménez, J., and Martinez-Ferrer, G. 1996. The taxonomic position of the causal agent of Acremonium collapse. Mycologia 88:804-808.

2. Armengol, J. 1997. Aspectos patológicos, epidemiológicos y culturales de Acremonium cucurbitacearum Alfaro-Garcia, W. Gams et J. Garcia-Jiménez. Ph.D. diss. Universidad Politecnica de Valencia, Valencia, Spain.

3. Armengol, J., Martínez-Ferrer, G., Sanz, E., Bruton, B. D., and García-Jiménez, J. 1996. Influencia de la fecha de observación y la densidad de inóculo en la patogenicidad de Acremonium cucurbitacearum a melón. (Abstr.) VIII Congr. Nac. Soc. Española Fitopatol. p. 181.

4. Armengol, J., Martínez-Ferrer, G., Sanz, E., Bruton, B. D., and García-Jiménez, J. 1998. Host range of Acremonium cucurbitacearum, cause of acremonium collapse of muskmelon. Plant Pathol. 47:29-35.

5. Baker, R. 1971. Analysis involving inoculum density of soil-borne plant pathogens in epidemiology. Phytopathology 61:1280-1292.
6. Baker, R., Maurer, C. L., and Maurer, R. A. 1967. Ecology of plant pathogens in soil. VII Mathematical models and inoculum density. Phytopathology 57:662-666.

7. Bruton, B. D. 1998. Soilborne diseases in Cucurbitaceae: Pathogen virulence and host resistance. Pages 143-166 in: Cucurbitaceae '98. J. McCreight, ed. Am. Soc. Hortic. Sci., Alexandria, VA.

8. Bruton, B. D., Davis, R. M., and Gordon, T. R. 1995. Occurrence of Acremonium sp. and Monosporascus cannonballus in the major cantaloupe and watermelon growing areas of California. Plant Dis. 79:754.

9. Bruton, B. D., García-Jiménez, J., and Armengol, J. 1999. Analysis of the relationship between temperature and vine declines caused by Acremonium cucurbitacearum and Monsporascus cannonballus on muskmelon. Subtrop. Plant Sci. 51:23-28.

10. Bruton, B. D., García-Jiménez, J., Armengol, J., and Martínez-Ferrer, G. 1996. Colapso del melón en las provincias del este y del sur de España. (Abstr.) VIII Congr. Nac. Soc. Española Fitopatol. p. 124.

11. Bruton, B. D., Gordon, T. R., and Davis, R. M. 1995. Optimum CFU concentrations for testing pathogenicity of California cucurbit isolates of Monosporascus cannonballus and an Acremonium sp. (Abstr.) Phytopathology 85:1119.

12. Bruton, B. D., Miller, M. E., and GarcíaJiménez, J. 1996. Comparison of Acremonium sp. from the Lower Rio Grande Valley of Texas with Acremonium sp. from Spain. (Abstr.) Phytopathology S86:3.

13. Bruton, B. D., Popham, T. W., Garcia-Jimenez, J., Armengol, J., and Miller, M. E. Disease reaction among selected Cucurbitaceae to an Acremonium cucurbitacearum isolate from Texas. HortScience. In press.

14. Bruton, B. D., Russo, V. M., Garcia-Jimenez, J., and Miller, M. E. 1998. Carbohydrate partitioning, cultural practices, and vine decline diseases of cucurbits. Pages 189-200 in: $\mathrm{Cu}-$ curbitaceae'98. J. McCreight, ed. Am. Soc. Hortic. Sci., Alexandria, VA.

15. Garcia-Jimenez, J., Armengol, J., and Martinez-Ferrer, G. 1994. Puntos negros de la raíces de melón y sandia (Monosporascus sp.). Pages 38-42 in: Enfermedades de los Cucurbitaceas en Espana. J. R. Diaz Ruiz and J. Garcia-Jimenez, eds. Sociedad Espanola de Fitopatologia-Phytoma Espana.

16. García-Jiménez, J., Velázquez, T., and Alfaro, A. 1989. Secuencia de sintomas en el colapso del melon. Bol. San. Veg. Plagas 15:333-342.

17. García-Jiménez, J., Velázquez, T., Jorda, C., and Alfaro-García, A. 1994. Acremonium species as the causal agent of muskmelon collapse in Spain. Plant Dis. 78:416-419.

18. Grogan, R. G., Sall, M. A., and Punja, Z. K. 1980. Concepts for modeling root infection by soilborne fungi. Phytopathology 70:361363.

19. Gubler, W. D. 1982. Epidemiology and control of Cephalosporium root and hypocotyl rot of melon in California. Ph.D. thesis. University of California, Davis.

20. Gwynne, B. J., Davis, R. M., and Gordon, T. R. 1997. Occurrence and pathogenicity of fungi associated with melon vine decline in California. (Abstr.) Phytopathology 87:S37.

21. Karlatti, R. S., Abdeen, F. M., and Al-Fehaid, M. S. 1997. First report of Monosporascus cannonballus on melons in Saudi Arabia. Plant Dis. 81:1215.

22. Kim, D. H., Rasmussen, S. L., and Stangellini, M. E. 1995. Monosporascus cannonballus root rot of muskmelon: Root infection and symptom development in relation to soil temperature. (Abstr.) Phytopathology 85:1195.

23. Lobo-Ruano, M. 1990. Colapso del melon 
producido por hongos del genero Monosporascus. Bol. San. Veg. Plagas 16:701-707.

24. Lobo-Ruano, M. 1991. Las graves alteraciones de melonares y sandiares. Bol. San. Veg. Plagas 17:133-163.

25. Lovic, B. R., Martyn, R. D., and Lobo, M. 1996. Agresividad de los aislados Españoles de Monosporascus cannonballus. (Abstr.) VIII Congr. Nac. Soc. Española Fitopatol. p. 139.

26. Lovic, B. R., Martyn, R. D., and Miller, M. E. 1993. Pathogenicity of Monosporascus cannonballus as related to colony characteristics and geographic origin. (Abstr.) Phytopathology 83:466.

27. Lovic, B. R., Martyn, R. D., and Miller, M. E. 1995. Sequence analysis of the ITS regions of rDNA in Monosporascus spp. to evaluate it potential for PCR-mediated detection. Phytopathology 85:655-661.

28. Lovic, B. R., Valdez, V. A., Martyn, R. D., and Miller, M. E. 1994. Association of dsRNA with reduced aggressiveness and phenotypic variability in Monosporascus cannonballus. (Abstr.) Phytopathology 84:776.

29. Martyn, R. D., Batten, J. S., Park, Y.-J., and Miller, M. E. 1996. First report of Monosporascus root rot/vine decline of watermelon in Mexico. Plant Dis. 80:1430.

30. Martyn, R. D., and Miller, M. E. 1996. Mono- sporascus root rot and vine decline an emerging disease of melons worldwide. Plant Dis. 80:716-725.

31. Mertely, J. C., Martyn, R. D., Miller, M. E., and Bruton, B. D. 1991. Role of Monosporascus cannonballus and other fungi in a root rot/vine decline disease of muskmelon. Plant Dis. 75:1133-1137.

32. Mertely, J. C., Martyn, R. D., Miller, M. E., and Bruton, B. D. 1993. An expanded host range for the muskmelon pathogen Monosporascus cannonballus. Plant Dis. 77:667-673.

33. Mertely, J. C., Martyn, R. D., Miller, M. E., and Bruton, B. D. 1993. Quantification of Monosporascus cannonballus ascospores in three commercial muskmelon fields in south Texas. Plant Dis. 77:766-771.

34. Miller, M. E., Martyn, R. D., Lovic, B. R., and Bruton, B. D. 1995. An overview of vine decline diseases of melons. Pages 31-35 in: Cucurbitaceae '94, G. Lester and J. Dunlap, eds. Gateway Printing, Edinburg, TX.

35. Park, Y.-J., Martyn, R. D., and Miller, M. E. 1996. dsRNA is responsible for cultural aberrations in Monosporascus cannonballus and hypovirulence to muskmelon. (Abstr.) Phytopathology 86:S107.

36. Pivonia, S., Cohen, R., Kafkafi, U., Ben Ze'ev, I. S., and Katan, J. 1997. Sudden wilt of melons in southern Israel: Fungal agents and relationship with plant development.
Plant Dis. 81:1264-1268.

37. Popham, T. W., Bruton, B. D., Armengol, J., and Garcia-Jimenez, J. 1998. Assessment of virulence of Acremonium cucurbitacearum using multiple colony forming units and plan responses. (Abstr.) Phytopathology 88:S72.

38. Reuveni, R., Krikun, J., and Shani, U. 1983 The role of Monosporascus cannonballus in a collapse of melon plants in an arid area of Israel. Phytopathology 73:1223-1226.

39. Stanghellini, M. E., Kim, D. H., and Rasmussen, S. L. 1996. Ascospores of Monosporascus cannonballus: Germination and distribution in cultivated and desert soils in Arizona. Phytopathology 86:509-514.

40. Tsay, J.-G., and Tung, B.-K. 1995. The occurrence of Monosporascus root rot/vine decline of muskmelon in Taiwan. Plant Pathol. Bull. 4:25-29.

41. Uematsu, S., Onogi, S., and Watanabe, T. T. 1985. Pathogenicity of Monosporascus cannonballus Pollack and Uecker in relation to melon root rot in Japan. Ann. Phytopathol. Soc. Jpn. 51:272-276.

42. Uematsu, S., and Sekiyama, K. 1990. Comparison of morphological characteristics and pathogenicity of Monosporascus cannonbal lus Pollack and Uecker collected in Japan, distribution in melon plants with root rot symptoms, and survival in soils under laboratory conditions. Soil Microorg. 35:7-12. 